\title{
Representation vs. Participation of Female Students in Class: A Comparative Feminist Investigation
}

\author{
Gudetu W. Bortola \\ Department of Cooperatives Business Management, Wollega University, Nekemte, Ethiopia \\ Email: seenaafjiraataa@gmail.com
}

Received 3 August 2015; accepted 19 August 2015; published 26 August 2015

Copyright (C) 2015 by author and OALib.

This work is licensed under the Creative Commons Attribution International License (CC BY). http://creativecommons.org/licenses/by/4.0/

(c) (i) Open Access

\begin{abstract}
Even though Education is most important to pursue the objective of women's empowerment, gender imbalance that prevails at various levels of schooling has been a hampering factor. Besides enrollment, gender disparity manifests in areas of class participation and achievement in higher education institutions. In Ethiopia, even if through several interventions, the enrollment of female students at various levels of schooling has dramatically been increased, questions like in class participation and achievement remain unanswered. This piece of writing, while investigating the issues of representation vs. participation has an objective of assessing why female students' participation in class is low compared to male counterparts. Applying feminist qualitative research, this study identifies that shyness, language proficiency, family background, instructor's affiliation to active students, environment, and lack of value attached to participation in class were having impacts on female students participation in class. In contrast, representation in class compared to male counterpart was not a decisive factor. And the researcher concludes that, unless otherwise interventions to enhance females education in Ethiopia further investigate the issues of in class participation and achievement, the so far efforts have been only tip of the iceberg.
\end{abstract}

\section{Keywords}

Feminism, Gender Disparity, Gender and Education, Participation, Representation

Subject Areas: Anthropology

\section{Introduction}

Education is perhaps the single most important source of empowerment to women. Every step to empowerment begins with awareness of potentialities within and education helps to recognize that. In the $21^{\text {st }}$ century, where 
educational achievement is becoming an issue of prestige, success of women in the higher education is of a paramount contribution.

Plenty of literatures disclose that at the beginning of human history, the environment favored and promoted equality of males and females. However, as the exposure of males to the natural environment differed, various activities and dangers increased, both sexes started to differ in the nature and depth of experience [1]. Since then, the gender disparity that began in this way was widened by religious, political, economic, cultural and other factors. Currently, gender differentiations are reflected in the accesses to the three precious things of the world, political power, economic privileges and social or cultural prestige [1]. The differentiations with no doubt are the results of prevailing imbalances in access to and success from educational streams in particular, the higher one. Ethiopian women are not exceptional to this phenomenon, where educational advancement of women has been hampered by several overlapping factors, from which social, cultural and political set up of the society could be mentioned. In response to the past historical damages, the contemporary government has been taking relentless efforts in the past two decades and an improvement has been achieved in areas of enrollment.

To mention few, the 1995 Constitution of the Federal Democratic Republic of Ethiopia under article 35 [2] has decreed women's equal right in all aspects of the society including the educational sector. Besides, women's policy which was issued in 1991 has determinedly emphasized on the fact that the need of women's advancement in education and enrollment has dramatically been increased [3].

Even if through several efforts females' enrollment in educational sectors has been increased in Ethiopia, their participation in class remains low compared to male counterparts.

Females' representation in schools and classes is lower than male counterparts and their participation insignificant. Participating in class gives females the ability to express their feelings regarding the subject matter through which self confidence is built and hence a signal of empowerment. Empowerment through education plays unequivocal role for all other sorts of empowerment to females and women. Representation in class does not show a true beginning of empowerment in the eyes of the investigator, but it is found to be good to question what female students' interaction in the class is? Hence, this research examines the participation of female students in class as related to their representation.

This research is undertaken in Wollega University, College of Business and Economics, Department of Cooperatives of the three streams ( 1 - 3 years). The number of female students in the first and third year classes was smaller than that of males, but as luck would have it, females surpass males in the second year class. The root of this research is the researcher's experience of female students in the three streams as a course instructor. In all the three streams female's participation is very low. So far no deep academic investigation has been undertaken regarding the topic under discussion. Hence, the researcher believes that by comparative investigation of classes having relatively lower and higher number of female students, we can try to examine why female students' participation is low compared to male counterparts.

\section{Objectives}

1) To identify factors that affect female student's participation in class;

2) To assess if the representation of female students in class in relation to male counterpart has an impact on their participation.

\section{Methodology}

This study applies qualitative method of feminist nature. The philosophical assumption behind this design is social constructivist. As social constructivists, many qualitative researchers posit that all types of knowledge are constructed within the cognitive framework and theoretical concepts of an individual: therefore all understandings of the external world are not reflections of it, but are solely subjective interpretations [4]. From this perspective, all knowledge is predicated on the values, ideas and judgments of the individual, and is locally and contextually defined [5]. The idea of situated knowledge links feminist stand point research and social constructivists. Hence using social constructivist as a philosophical background for the research is found to be relevant in order to value female students lived experience.

Qualitative primary data sources were used to conduct this research. These were collected through in-depth interview, focus group discussion and systematic observation. The methods were very helpful to triangulate the finding with different data sources. For the interview and focus group discussion, female students from the three 
classes were purposively selected. The statistics of female to male ratio in the identified class is depicted in Table 1.

From Table 1, it becomes clear that in the two years of study, i.e. the first and the third one, the number of female students compared to male counterparts is nominal while it is the vice versa in the first year.

Accordingly, based on the two principles of selecting the appropriate samples for qualitative research (saturation of information and sufficiency of the samples); the researcher did an interview with female students of the three years of study. The principle of saturation of information has only been employed for the second year female students as their number is relatively high. Hence, about twenty three female students have been included for the interview and six for the focus group discussion. The details are 15 female students from the second year, five from the first year, and three from the third year. And for the focus group discussion female students who were not included in the interview have been selected. Besides, systematic observation in advance of the interview and FGD has also been made by the investigator.

As regards secondary sources, except in the case that different literature has been reviewed either to confirm or contradict with the finding of this research, no other records showing the trend of female students participating in class has been used to build up the primary one. As it is recommended by [6] qualitative analysis method was used to give meaning to collected data.

\section{Validity and Trustworthiness of the Study}

In order to ensure validity of this study, different data sources were triangulated. This was done by examining evidences from different sources like systematic observation during lectures, in-depth interview with female students and Focus group discussion.

To keep the research ethical and academic, the researcher took every possible precaution to refrain from doing any unethical works. Participants were informed about the purpose of the study and the use of the data. The consent form was prepared on which both participants and the researcher signed. Accordingly, data collection was based on the full consent of participants.

\section{Discussion of the Results}

The present section introduced you to the background, objectives and methodological framework of the research. Under this chapter the results will be presented and discussed in detail.

\subsection{Factors Affecting Female Students' Participation in Class}

As lived experience witness and literatures also disclose, female student's active participation at every level of educational structure is low. The core of this research is also low participation of female students in an organized class room setting. In the current study, different forms of class participation has been examined, such as raising one's hand versus the more aggressive style of interrupting, as well as students' perceptions of the length of their interactions. In all these situations female student's interaction was found to be low and the research objective was to question why this happens so.

The discussion was based on the data gathered from in-depth interview, systematic observation and focus group discussion done by the researcher. From these evidences the following reasons could be identified. The reasons mentioned by even a single student were incorporated, as the lived experience matters in feminist research.

Table 1. Total number of students at the Department.

\begin{tabular}{ccccccccccc}
\hline & \multicolumn{9}{c}{ Year of Study } \\
\hline & Year 1 & \multicolumn{3}{c}{ Year II } & & \multicolumn{2}{c}{ Year III } \\
\hline Students & Male & Female & Total & Male & Female & Total & Male & Female & Total \\
\hline & 13 & 20 & 33 & 29 & 7 & 36 & 21 & 4 & 25 \\
\hline
\end{tabular}

Source: Students record at the Department, February, 2014. 


\section{Shyness}

Ethiopia is one of the developing countries characterized by multinational, multi lingual and multi cultural society. Each nation has its own tradition and cultural setting by which member of the society are identified with. Even if each nation has its own culture that identifies its people from the other nation, all nations' culture shares one common thing, i.e. the status given to women is negligible. The glorification given to men compared to women which can be manifested for the fact that men has been dominating all the political and social prestige's, the incapacity and irrationality attached to women, which marginalizes women from equally bearing offices and serving the nation are all what the culture carries with it in Ethiopia.

As a result women's submission to what the culture dictates kept them from fully expressing their potentials and feelings. In that case women are expected to be silent, cool and decent to pursue acceptance in the eyes of the society. And all other women born to that culture are also expected to behave the same way through socialization process. The scope of the research does not allow to extend beyond what has been stated, and it is worthless mentioning all what the drawbacks women in Ethiopia has been shouldering because of the so-called cultural and traditional settings of the society, the trouble still exists besides tremendous interventions.

Shyness which keeps women from exploiting their potentials to the fullest possible level therefore is the result of culture and at all level of schooling and other socio political settings Ethiopian women are seen while simply approving the decisions passed by men by applause. In particular in rural areas if the society encounters talkative women, this is exception and that woman lacks adherence to the culture's demand. This is general and it was written based on what female students stated for their low participation in class starting from their experiences from the beginning. And here is what one female student from the class has stated during the interview.

"As it is known, the society where I was born and grown up in doesn't encourage women to equally talk with men, and I inherited this manner from my mother, that is why I fear to talk. When incidentally teachers ask me to respond, my body trembles in my shoes. I always pass the chance by keeping silent.

The above narration tells how the socialization process keeps females to be silent. This shows that as boys are expected to act like their fathers, females should take after their mothers. Hence shyness was repeatedly mentioned by female students as the cause for their low participation in class.

Language proficiency

Besides shyness, female students mentioned the language imperfectness as a big problem for their participation in class. The medium of instruction in Ethiopian higher learning institutions is English. Even though, English language is included as one subject from the lower class to the upper level of turning to University, it is rare to find students that fully express themselves using English. But few students whose families could afford and get them join private schools do communicate well in English. Given the living standard of majority of Ethiopian people, it is not difficult to guess that the families could not afford for the private schools. Turning to the point under discussion, the problem doubles itself for female students. Besides female student's low enrollment in schools particularly in rural areas, their achievement in all subjects compared to male counterpart is not impressive. But exceptions do exist. Ample evidences could be mentioned; and the big one is sharing mothers' household burden. In rural areas girls are seen while fetching water, looking after their baby sisters and brothers, collecting fire wood, travelling long distances carrying loads on their backs, cooking and generally discharging house hold responsibilities accompanying their mothers. The gender division of labor that manifest in many other cultures is very prominent in Ethiopia and there is no house hold work sharing among men and women, females and boys. That is why female students' achievement not only in English language but in all other subjects is relatively low. Hence, lack of fluently communicating in English language as it has been mentioned by female students under investigation and also confirmed by the researchers teaching experience was the big problem for low participation.

\section{Teachers/Instructors affiliation to active students}

Human nature is not similar; all has got its own distinctive personality. As a result of diverse personality the behaviors people reflect in their social interactions like social gatherings, community and public meetings is also dissimilar. The same way students learn in a mixed up settings, students from different social, economical and cultural background come together and make up a full class in Universities. Some students like to talk and others want to be triggered by someone else or the teacher to speak out. In most cases students who start talking at the first time would continue dominating the classes, leaving no room for the shy and silent students. In that case the role of unspeaking students remains passively listening to the conversation between active students and the teacher. Female students in most cases are categorized under the mute group. As combined factors would cause 
for their silence, teachers should instigate females to react in the class and should not chase the active students only. The systematic observation done by the researcher has also verified the situation.

\section{Family background}

As it was discussed above, males and females grow up in different manner. While some families give complete freedom to male, denying females the equality right within the household, very few may privilege both male and female. Given the culture bounded nature of Ethiopian society, there is a long way to walk to bring gender equality. Changing the so called cultural settings of the community requires radical change in the attitude of men, women, boys and girls. The early child hood experiences of the ways in which males and females have been treated by their families do have a significant impact throughout their schooling life.

\section{Environmental impact}

The environment within which female students grown up has also a detrimental impact on their academic performance. The researcher here wanted to compare female students who came from urban areas and those from rural areas. While students with urban background have more exposure to technological advancements like access to media, they are more experienced and perform better in class. As rural residents significantly surpass urban in Ethiopia, the same is true in the class under investigation where majority of female students are from rural areas. Hence having rural background where the society is highly tied to the so called traditional way of life and way of acting in different places, this will impede female student's confidence to speak and react in an organized active class room teaching.

\section{Instructors' Sex}

Female students in most cases make close contact with female instructors and hence have a confidence to speak than when the instructor is male. As it is true in all public and private colleges and Universities in Ethiopia, the number of female instructors in Wollega University is very few compared to male instructors. Only few departments have got one or two female instructors. Luckily, the department under investigation has two female instructors including the researcher. Except for some social helps and support, female student's participation in the stated department remains low regardless of the gender of the instructor. This can lead to a rough conclusion that female student's in class participation remains the same regardless of the sex of instructors taking a particular course.

\section{Fear of speaking in mixed group}

Literatures disclose that women and females talk and participate more when the group is pure women. The researcher's experience of women's interaction on women only seminars, meetings and discussions also verify the literature. Female students who were interviewed and also discussed the focus group stated that they fear to talk while being seated in a class with mixed group. There is a difference of participation between when the class is purely female and when it is combination of both sexes. When female students are given tutorial classes their reaction is different. Not only in formally organized class having students and instructors, but also in a very informal groups of a mixed type, women fear to talk in front of men and hence give precedence. This phenomenon continued to manifest in lower grades through University.

\section{Lack of value attachment to participation}

Most of the interviewed students stated that whatever participation is high or low in class, no values is attached to it. Therefore they consider as silence is gold and they only strive to perform during the exam. But in $21^{\text {st }}$ century, "silence is old and participation is gold".

\subsection{Representation versus Participation in Class}

Different factors have been identified for female student's low participation in class. In addition to the above factors, the researcher has come to investigate whether the number of female students in class compared to male counterparts has an impact on their participation. The base for focusing on this factor is the investigator's personal experience through teaching repeated courses of the aforementioned classes having relatively lower number of female students compared to male counterparts and classes having relatively higher number of female students compared to their male counterparts. Surprisingly enough, this investigation found out that regardless of their relative representation in class, female students participation remains low. The finding is confirmed by the long lasted data obtained through systematic observation, interview and focus group discussion. As it has been discussed under the methodology part of this paper, in the identified stream and year of study, the number of female students in the second year class considerably surpasses male counterparts. The aim was to do a com- 
parative investigation on classes having relatively high and low number of female students in class as contrasted with male students. In both cases due to the above listed factors analyzed from the horse's mouth of female students, the representation in class did not bear impact on female student's participation.

\section{Conclusion}

In conclusion, the researcher has been investigating why female student's participation in class is low compared to male counterparts. The study was done on female students of cooperative accounting and auditing at Wollega University, College of Business and Economics, department of Cooperatives of the three streams. Continued experience of the instructor has laid a ground for the commence of the investigation and the study was a comparative nature. A lot of investigations in areas of gender and education worldwide dictate that there is gender imbalance at every stage of schooling and the same is true in Ethiopia. Ethiopia is a culture bound society where the patriarchal social setting occupies a significant place. As patriarchal society glorifies the rule of men and relegates the values attached to women to secondary, women's pivotal role in the socio political setting of the nation remains unrecognized. Unlike the earlier periods, the contemporary government has a vision to bring gender equality in all social, political and economical spheres through continued and devoted females' education. But a lot of things remain under interrogation as regards female education in Ethiopia as majority of interventions has not yet been targeted towards identifying differentials in areas of in class participation and achievement. The researcher believes that unless these critical questions got a precise response, the efforts to bring gender equality in education in Ethiopia so far are only tip of the iceberg.

\section{Acknowledgements}

I would like to thank Horenus Wakgari, a sister of mine, who has always been at my side throughout the work of this article. My warm thanks also go to my brother, Bula Wakgari who has always been appreciating my works.

\section{Competing Interests}

The author declares that no competing interests exist.

\section{References}

[1] Power James (1975) The History of Western Education. Macmillan, New York.

[2] Federal Negaret Gazette (1995) The Constitution of the Federal Democratic Republic of Ethiopia, Addis Ababa, Ethiopia.

[3] Transitional Government of Ethiopia (1993) National Policy on Ethiopian Women, Addis Ababa, Ethiopia.

[4] Patton, M.Q. (2002) Qualitative Research and Evaluation Methods. Sage, Thousand Oaks, CA.

[5] Mark, D., et al. (2002) Explaining Society, Critical Realism in the Social Sciences. Rutledge, London.

[6] Creswell, J. (2009) Qualitative Inquiry and Research Design. Sage, Thousands Oak, CA. 